\title{
A LETTER FROM
}

\section{ALEXANDER TCHEREPNIN}

2. RUE DE FURstemberg. PARIB-VI*

$17 v 1962$

Dear Mr. Mitchell,

thank you for your Retter, and the kind reminder of our conversation in London concerning my contribution to the Tempo issue in celelration of Jgor Stravinsxy'> 80 " birthday. Ever since the time $S$ received your Retter in Chicago on the eve of my departure to Paris 3 was Riring happy moments recolfecting my encounters with Jgor Feodorovitch: the time 3 was still in short pants, and he came to our home in St. Petersbourg; the time when in the restaurant car of the Train bleu going to Paris from Monte Carlo $I$ had the elation of conversing in lenglat with him; the time of the american premiere of "Jeu des Cartes" in new York; the time of my visit at his home in Los angeles, en tête-a.tête with him and his dear wife, Vera Arturovna; finaly, the time, last autumn, we met at the Berlin Festival.

But when it came to write it down 3 felt that what means everything to me is of personal nature. I treasure it because of my profound admiration to the great $M$ aster, but if written down it would $b_{e}$ advantageous to me $b_{y}$ the simple fact that $I$ had the chance to be with him, yet hardly of general interest.

Indeed so much has been written about Stravinsky in all languages by practicaly every great musician of the world, that 3 .am shy to express what 3 geel so profoundly. I am sure, that your issue will be a success, that the contributions that you will have will be highly worthy and illuninating. Please forgire my "Cordelian" attitude which, as said, is dictated by my loring the great Master and the great Man above all.

$$
\begin{gathered}
\text { most sincerely } \\
\text { yours a. Teherepnim }
\end{gathered}
$$




\section{ROUND}
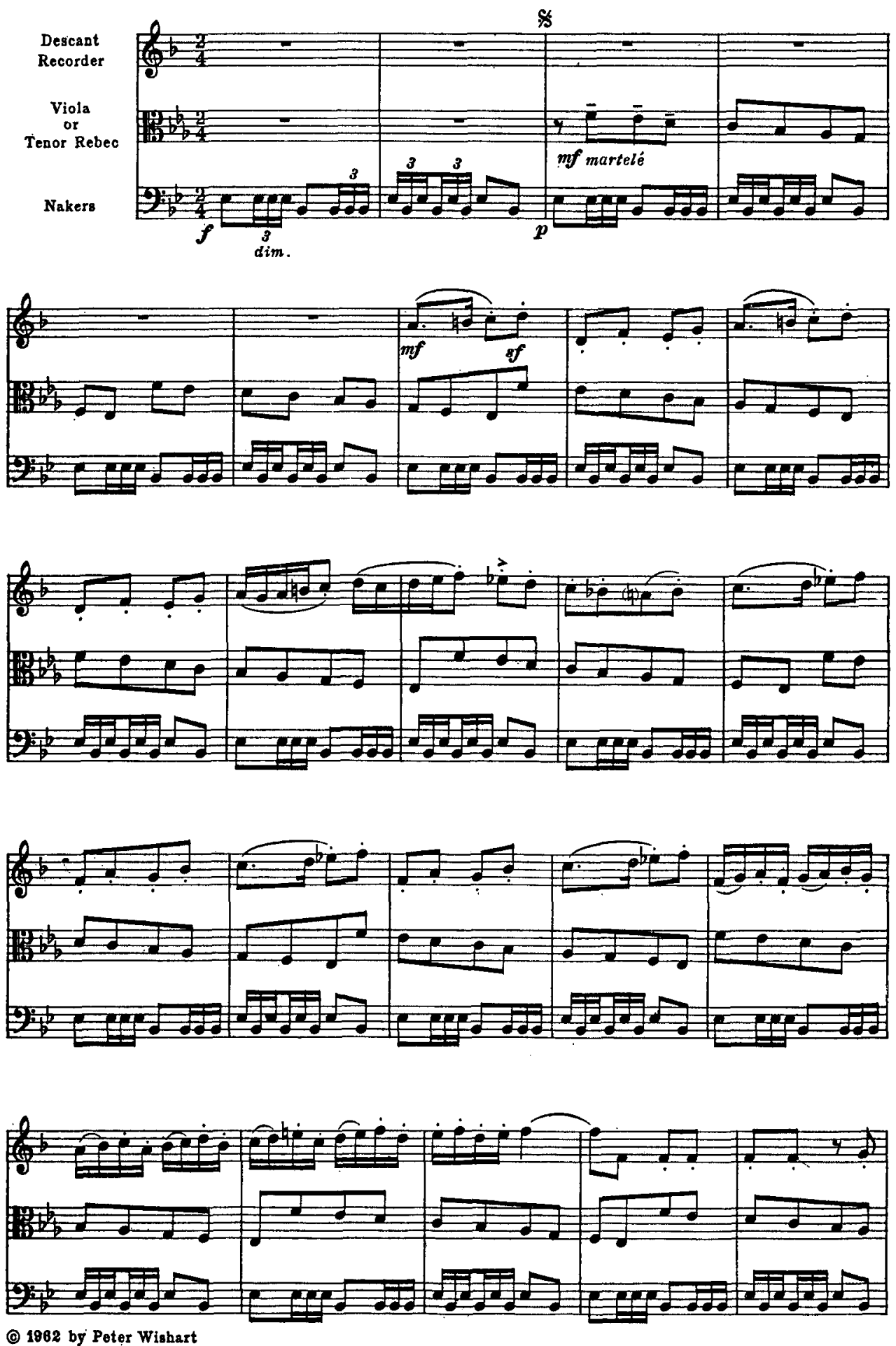

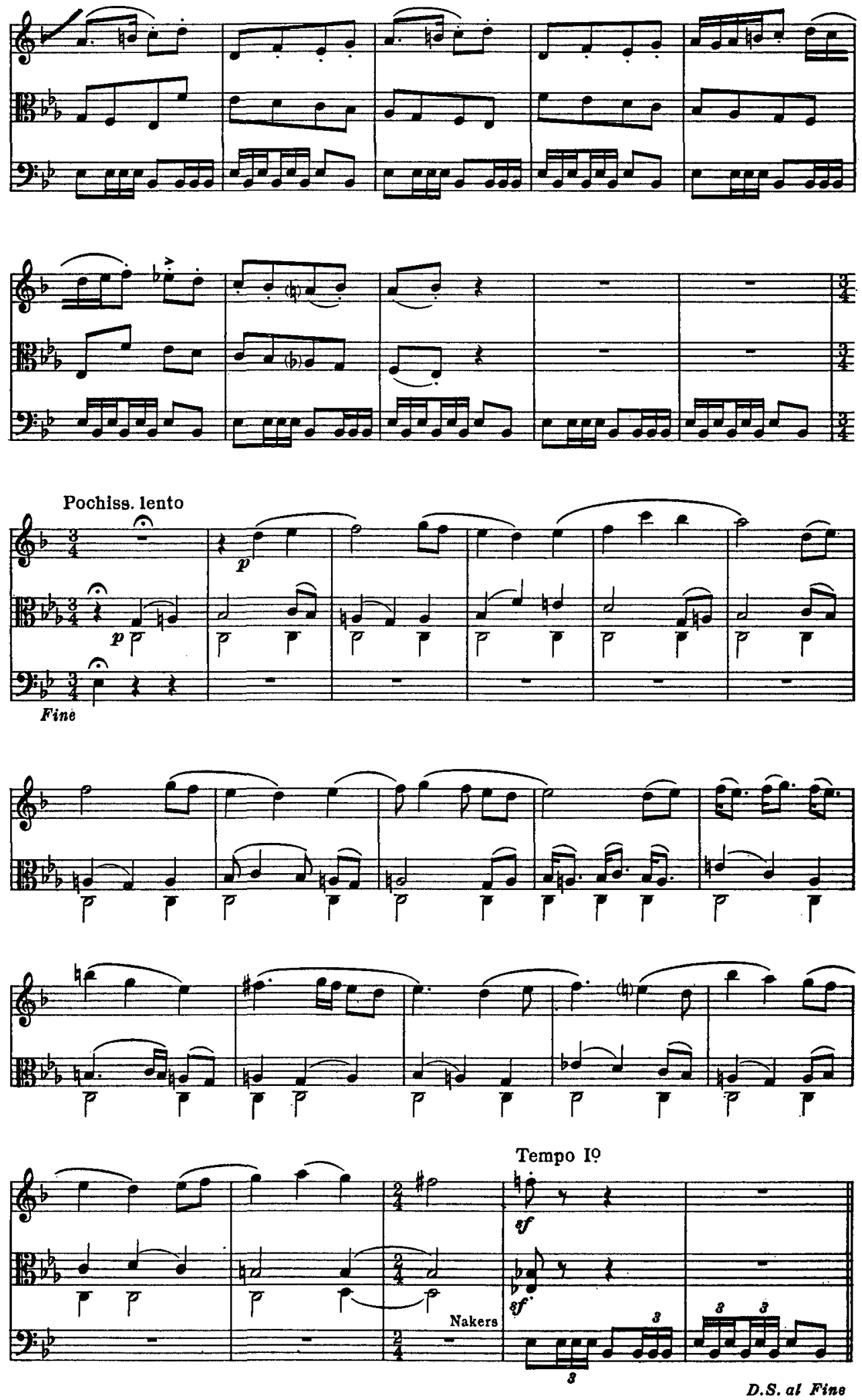